PALABRAS CLAVE

Globalización

Liberalización económica

Crecimiento económico

Desarrollo regional

Exportaciones

Inversión extranjera directa

Producto interno bruto

Análisis comparativo

Indicadores económicos

Chile

Juan Carlos Ramírez J.

Director, Instituto Latinoamericano y

del Caribe de Planificación Económica

y Social (ILPES)

œ juancarlos.ramirez@cepal.org

Iván Silva Lira

Jefe, Área de Gestión del Desarrollo

Local y Regional, ILPES

- ivan.silva@cepal.org
REVISTA DE LA CEPAL 95 AGOSTO 2008

\section{Globalización y desarrollo regional: evolución económica de las regiones chilenas, 1990-2002}

\author{
Juan Carlos Ramirez J. e Iván Silva Lira
}

$\mathrm{U}$

na inserción más profunda de la economía chilena en la economía global, basándose principalmente en el aprovechamiento de las ventajas comparativas del país, ha contribuido fuertemente a los cambios observados en la dinámica y la posición relativa de las regiones de Chile. Este artículo analiza y compara las dinámicas de crecimiento de esas regiones y explica sus comportamientos diferentes. Aquellas de mayor crecimiento se han insertado en la economía mundial gracias a sus recursos naturales renovables o no renovables, a procesos exportadores vinculados con actividades agroindustriales y a centros metropolitanos articulados con la economía mundial en la provisión de servicios financieros y comerciales. El crecimiento de algunas de las regiones no siempre se ha traducido en las mejoras sociales correspondientes, lo que reivindica la necesidad de políticas sociales explícitas. 


\section{I}

\section{Introducción}

El hecho de haberse profundizado la inserción de la economía chilena en la economía global es uno de los factores más relevantes que están tras el conjunto de cambios en la dinámica y en la posición relativa de las regiones de Chile. Esta inserción se ha debido sobre todo al aprovechamiento de las ventajas comparativas el país. El sector exportador, basado principalmente en productos primarios y semielaborados, se transformó en la fuerza motriz del crecimiento económico. Así, la participación de las exportaciones en el producto interno bruto (PIB) se elevó en promedio del $20 \%$ al $40 \%$ del PIB entre fines de los años 1970 y fines de los años 1990.

Un componente del ciclo económico y de su evolución es la existencia de focos, nodos o centros geográficos innovadores, generadores de cambios que arrastran al conjunto en forma selectiva: a algunos con más intensidad, a otros marginalmente, mientras que a algunos otros los deja totalmente excluidos. Los efectos de arrastre se establecen a través de procesos de difusión espacial que tienen patrones característicos. Durante estos procesos de arrastre y difusión, los distintos componentes del conjunto (red urbana, región nación) se transforman a ritmos diferentes de acercamiento (convergencia), cuando los territorios de menor desarrollo relativo avanzan más rápidamente que los de mayor desarrollo, y de alejamiento (divergencia), cuando sucede lo opuesto.

En este artículo se intenta, a través de distintas técnicas de análisis regional, examinar y comparar las dinámicas de crecimiento de las regiones chilenas para establecer a cuáles les está yendo bien y a cuáles mal y, a partir de ese estudio, ofrecer una explicación de esos comportamientos diversos. En definitiva, se trata de averiguar la causa de que, a partir de los años 1990, no haya habido indicios de convergencia, aunque las disparidades tampoco parecen haber aumentado.

En ambos casos (de convergencia y de divergencia), se trata de buscar los factores comunes que dan lugar a esta capacidad de crecimiento, para saber si los efectos de arrastre se pueden prever o si son fenómenos que necesitan otras condiciones objetivas de desarrollo, acompañadas de cierto tipo de políticas regionales explícitas.

\section{II}

\section{Inserción externa de las regiones chilenas}

En términos regionales, la intensidad del desarrollo exportador se manifiesta en el hecho de que en el período 1990-1992 solo tres regiones exportaron más de mil millones de dólares, mientras que en el período 2003-2005 dicha cifra fue superada por nueve regiones (cuadro 1 ).

Este proceso ha sido particularmente intenso en las regiones con estructuras exportadoras de productos básicos (commodities), entre ellas la minería del cobre, la fruticultura, la industria de productos forestales como la celulosa y las astillas (chips) de maderas

\footnotetext{
$\square$ Este artículo contó con la valiosa colaboración de Luis Riffo Pérez, particularmente en el procesamiento y análisis de la información sobre crecimiento y comercio exterior de las regiones chilenas.
}

y, más recientemente, la pesca. En algunos sectores las formas de organización productiva se han caracterizado por una elevada interacción de los actores, como lo destacan los estudios sobre aglomeraciones productivas (clusters). Entre esas aglomeraciones la más emblemática es la del salmón, pero también hay ejemplos importantes en la industria del vino y en la industria de la madera. ${ }^{1}$

Como se verá más adelante, en las regiones "ganadoras", particularmente la de Antofagasta, ha tenido un fuerte desarrollo la minería de exportación, vinculada a la aglomeración minera. En ella se ha dado gran importancia a la búsqueda de mejoras de gestión en la

\footnotetext{
1 Véase Muñoz (2008).
} 
CUADRO 1

Chile: exportaciones totales por regiones, 1990-2005

(Millones de dólares y porcentajes)

\begin{tabular}{|c|c|c|c|c|c|}
\hline \multirow{2}{*}{ Regiones } & \multicolumn{2}{|c|}{ 1990-1992 } & \multicolumn{2}{|c|}{ 2003-2005 } & \multirow{2}{*}{$\begin{array}{c}\text { Tasa promedio } \\
\text { de variación anual } \\
\%\end{array}$} \\
\hline & $\begin{array}{l}\text { Millones } \\
\text { de dólares }\end{array}$ & $\begin{array}{c}\text { Variación } \\
(\%)\end{array}$ & $\begin{array}{l}\text { Millones } \\
\text { de dólares }\end{array}$ & $\begin{array}{c}\text { Variación } \\
(\%)\end{array}$ & \\
\hline De Tarapacá & 278,3 & 68,0 & 1867,0 & 1037,2 & 15,8 \\
\hline De Antofagasta & 2662,6 & 650,4 & 8442,4 & 4690,2 & 9,3 \\
\hline De Atacama & 517,7 & 126,5 & 1442,2 & 801,2 & 8,2 \\
\hline De Coquimbo & 208,0 & 50,8 & 1328,8 & 738,2 & 15,0 \\
\hline De Valparaíso & 931,8 & 227,6 & 3049,6 & 1694,2 & 9,5 \\
\hline De O'Higgins & 872,5 & 213,1 & 2526,6 & 1403,7 & 8,2 \\
\hline Del Maule & 193,5 & 47,3 & 847,9 & 471,1 & 12,0 \\
\hline Del Bío Bío & 1227,8 & 299,9 & 3377,7 & 1876,5 & 8,1 \\
\hline De La Araucanía & 43,1 & 10,5 & 267,1 & 148,4 & 15,1 \\
\hline De Los Lagos & 347,2 & 84,8 & 1760,3 & 977,9 & 13,3 \\
\hline De Aysén & 69,4 & 17,0 & 259,4 & 144,1 & 10,7 \\
\hline De Magallanes & 156,6 & 38,3 & 726,6 & 403,7 & 12,5 \\
\hline R. Metropolitana & 1251,2 & 305,6 & 3804,1 & 2113,4 & 8,9 \\
\hline Otras & 409,4 & 100,0 & 180,0 & 100,0 & $-6,1$ \\
\hline Total & 9169,1 & 2239,6 & 29879,7 & 16599,8 & 9,5 \\
\hline
\end{tabular}

Fuente: elaboración propia con datos del Ministerio de Planificación y Cooperación (MIDEPLAN).

adquisición y manejo de materiales y, por lo tanto, en la integración de la cadena de proveedores, con el fin de lograr una mayor eficiencia en materia de costos, calidad y tiempo que podría tener efectos favorables sobre la economía regional. Por otra parte, en las regiones "convergentes" —las que están creciendo más que el promedio nacional, como las regiones de Los Lagos y Maule - no parece casual que en la primera haya tenido un interesante desarrollo la aglomeración productiva en torno al salmón, y en la segunda, aquella en torno al vino. Es decir, las aglomeraciones de este tipo parecen estar teniendo efectos positivos en las economías de esas regiones.

No ocurre lo mismo, sin embargo, en la Región del Bío Bío, tipificada más adelante como "estancada". En ella, la evolución satisfactoria de la industria forestal y el dinamismo exportador que la región ha exhibido no se han traducido en crecimiento dinámico ni en mejoras significativas de sus indicadores sociales.

En el cuadro 2 se identifican los principales subsectores exportadores en el período 2003-2005 y el peso relativo de las principales regiones en cada subsector. Cabe destacar que:

- el $86 \%$ de las exportaciones de cobre y hierro se generan en las regiones de Antofagasta, Tarapacá, Atacama y Valparaíso;
- cerca del 70\% de las exportaciones de la industria alimentaria (incluida la del salmón) proviene de la Región de Los Lagos, la Región Metropolitana de Santiago (en adelante Región Metropolitana) y la del Bío Bío;

- el $80 \%$ de las exportaciones de fruta proviene de las regiones de Valparaíso, del Maule, de O'Higgins y Metropolitana;

- los productos forestales como celulosa, papel y cartón se originan mayoritariamente en la Región del Bío Bío;

- los productos químicos básicos provienen de las regiones de Antofagasta, Metropolitana y de Magallanes (en este caso, principalmente metanol). La refinación de petróleo y productos derivados se efectúa principalmente en las regiones de Valparaíso y del Bío Bío;

- la producción de bebidas, líquidos y alcoholes (incluida la de vino) se concentra en la Región Metropolitana, la Región del Libertador Bernardo O'Higgins (en adelante Región de O'Higgins) y la Región del Maule.

Otra variable que ilustra la profundidad del proceso de inserción externa de Chile, especialmente durante los años 1990, es el incremento notable de la afluencia de inversión extranjera directa (IED). El nuevo tratamiento a la IED impulsado desde los años 1980 
CUADRO 2

Chile: distribución de los principales subsectores exportadores, por principales regiones de origen, 2003-2005

(Porcentajes, promedios)

\begin{tabular}{|c|c|c|c|c|c|c|c|c|c|}
\hline Regiones & $\begin{array}{c}\text { Cobre y } \\
\text { hierro }\end{array}$ & $\begin{array}{l}\text { Industria } \\
\text { de alimentos }\end{array}$ & Fruta & $\begin{array}{l}\text { Actividad } \\
\text { forestal }\end{array}$ & $\begin{array}{l}\text { Fabricación de } \\
\text { celulosa, papel } \\
\text { y cartón }\end{array}$ & $\begin{array}{l}\text { Productos } \\
\text { químicos } \\
\text { básicos }\end{array}$ & $\begin{array}{c}\text { Refinación de } \\
\text { petróleo y } \\
\text { productos } \\
\text { derivados }\end{array}$ & $\begin{array}{l}\text { Bebidas, } \\
\text { líquidos y } \\
\text { alcoholes }\end{array}$ & Resto \\
\hline De Tarapacá & 10,5 & & & & & & & & \\
\hline De Antofagasta & 55,8 & & & & & 18,0 & & & \\
\hline De Atacama & 9,2 & & & & & & & & \\
\hline \multicolumn{10}{|l|}{ De Coquimbo } \\
\hline De Valparaíso & 10,9 & & 25,5 & & & & 55,8 & & 8,5 \\
\hline R. Metropolitana & & 13,3 & 14,4 & & & 21,0 & & 52,1 & 59,9 \\
\hline De O’Higgins & & & 26,3 & & & & & 13,1 & \\
\hline Del Maule & & & 13,3 & & 17,2 & & & 22,0 & \\
\hline Del Bío Bío & & 13,8 & & 85,6 & 62,1 & & 27,7 & & 8,8 \\
\hline De La Araucanía & & & & & 12,8 & & & & \\
\hline De Los Lagos & & 40,2 & & & & & & & \\
\hline \multicolumn{10}{|l|}{ De Aysén } \\
\hline De Magallanes & & & & & & 44,6 & & & \\
\hline Subtotal & 86,4 & 67,3 & 79,5 & 85,6 & 92,1 & 83,6 & 83,5 & 87,2 & 77,2 \\
\hline Millones de dólares & 13205 & 3912 & 1569 & 1528 & 1454 & 1087 & 1015 & 837 & 2483 \\
\hline
\end{tabular}

Fuente: elaboración propia con datos del MIDEPLAN.

buscó igualar las condiciones ofrecidas a inversores extranjeros y locales, mediante medidas vinculadas, entre otras, a la flexibilización de los requisitos para el ingreso y salida de capitales y a la legislación tributaria (Moguillansky, 1999).

No obstante lo anterior, las corrientes de IED se mantuvieron en niveles relativamente bajos durante el régimen militar, para luego mostrar un fuerte incremento a partir del retorno al régimen democrático. En efecto, mientras que el total acumulado de IED entre 1974 y 1989 alcanzó a 5.100 millones de dólares, en el periodo 1990-2006 llegó a 58.400 millones de dólares, a pesar de que a partir del año 2000 se observó una marcada reducción, producto de las fuertes turbulencias internacionales que afectaron a toda América Latina (CEPAL, 2001).

Cabe subrayar que las corrientes de IED multirregional (es decir, sin localización en regiones determinadas) representaron casi el $40 \%$ de las corrientes totales en 19902006, situación que se debió principalmente a inversiones en los sectores de telecomunicacionesy de servicios de utilidad pública, como el de energía eléctrica.

En el período 1990-2006, la Región Metropolitana fue la que exhibió la mayor afluencia de IED materializada —un total de 15.275 millones de dólares_-, superando largamente al resto de las regiones. La siguieron las regiones de Antofagasta con 8.271 millones, Tarapacá con 3.375 millones y Atacama con 2.449 millones, y luego las regiones de Coquimbo, de Valparaíso, del Bío Bío y de Magallanes, con 1.000 a 2.000 millones. La Región de Los Lagos y la del Maule se ubicaron en torno a los 500 millones, y por último, la Región de La Araucanía, la Región de O’Higgins y la Región de Aysén del General Carlos Ibáñez del Campo (en adelante Región de Aysén) exhibieron cifras menores (cuadro 3).

En cuanto a los sectores productivos de destino, la IED materializada se concentró fuertemente en actividades orientadas a la exportación. Así, en la zona norte del país las corrientes de IED acumuladas en el total del período 1990-2006 se concentraron fuertemente en la minería: el 93\% de ellas en la Región de Antofagasta, 98\% en la de Tarapacá, 99\% en la de Atacama y 94\% en la de Coquimbo (cuadro 4).

En la zona central la afluencia de IED apuntó mayoritariamente a la Región Metropolitana, y se orientó sobre todo a la minería y los servicios financieros, aunque también hubo montos significativos dirigidos 
CUADRO 3

Chile: inversión extranjera directa materializada, ${ }^{\mathrm{a}}$ por regiones, 1974-2006 (Millones de dólares y porcentajes)

\begin{tabular}{|c|c|c|c|c|}
\hline \multirow{2}{*}{ Regiones } & \multicolumn{2}{|c|}{$\begin{array}{l}\text { IED acumulada } \\
1974-1989\end{array}$} & \multicolumn{2}{|c|}{$\begin{array}{l}\text { IED acumulada } \\
1990-2004\end{array}$} \\
\hline & $\begin{array}{l}\text { Millones } \\
\text { de dólares }\end{array}$ & $\%$ & $\begin{array}{l}\text { Millones } \\
\text { de dólares }\end{array}$ & $\%$ \\
\hline De Tarapacá & 68 & 1,3 & 3375 & 5,8 \\
\hline De Antofagasta & 665 & 13,0 & 8271 & 14,2 \\
\hline De Atacama & 121 & 2,4 & 2449 & 4,2 \\
\hline De Coquimbo & 210 & 4,1 & 1695 & 2,9 \\
\hline De Valparaíso & 88 & 1,7 & 1030 & 1,8 \\
\hline De O'Higgins & 20 & 0,4 & 264 & 0,5 \\
\hline Del Maule & 86 & 1,7 & 478 & 0,8 \\
\hline De Bío Bío & 55 & 1,1 & 988 & 1,7 \\
\hline De La Araucanía & 9 & 0,2 & 77 & 0,1 \\
\hline De Los Lagos & 95 & 1,9 & 495 & 0,8 \\
\hline De Aysén & 6 & 0,1 & 193 & 0,3 \\
\hline De Magallanes & 303 & 5,9 & 964 & 1,7 \\
\hline R. Metropolitana & 2693 & 52,7 & 15275 & 26,2 \\
\hline IED multirregional & 693 & 13,6 & 22850 & 39,1 \\
\hline Total & 5111 & 100,0 & 58405 & 100,0 \\
\hline
\end{tabular}

Fuente: elaboración propia con datos del Comité de Inversiones Extranjeras.

a En virtud del Decreto Ley No 600 de 1977, Estatuto de la Inversión Extranjera, Ley de cambios internacionales. a alimentos, productos químicos, electricidad, gas y agua, y al comercio. El segundo lugar lo ocupó la Región de Valparaíso, donde la IED se concentró en electricidad, gas y agua. El tercero, la del Bío Bío, que recibió corrientes de IED acumuladas dirigidas principalmente hacia electricidad, gas y agua y madera y papel. Más atrás se ubicaron la Región del Maule, con una IED concentrada en madera y papel, electricidad, gas y agua, y construcción; y la de O'Higgins, con afluencia de IED orientada principalmente a alimentos, bebidas y tabaco.

Finalmente, en la zona sur los mayores montos se dirigieron a la Región de Magallanes y la Antártica Chilena (en adelante Región de Magallanes), concentrándose en la industria química, principalmente en el metanol. En segundo lugar estuvo la Región de Los Lagos, con corrientes de IED más diversificadas que se distribuyeron entre alimentos, bebidas y tabaco, pesca y acuicultura, madera y papel, silvicultura y agricultura. En tercer lugar se ubicó la Región de Aysén, con EID orientada fundamentalmente a la minería. El cuarto lugar, por último, lo ocupó la Región de La Araucanía, donde las corrientes de IED tuvieron como destino principal la madera y el papel.

CUADRO 4

Chile: participación de los principales subsectores de destino de la inversión extranjera directa materializada, ${ }^{a}$ por región, acumulada 1990-2006 (Porcentajes)

\begin{tabular}{|c|c|c|c|c|c|c|c|c|c|c|c|c|c|c|c|}
\hline Sector/región & I & II & III & IV & V & VI & VII & VIII & IX & $\mathrm{X}$ & XI & XII & RMS & Multirregional & Total \\
\hline Agricultura & & & & & & 8,1 & & & 5,7 & & & & & & \\
\hline Silvicultura & & & & & & & 5,2 & & 9,0 & 15,0 & 5,9 & & & & \\
\hline Pesca y acuicultura & & & & & & & & & & 23,2 & 9,1 & & & & \\
\hline Minería y canteras & 98,3 & 93,2 & 99,7 & 94,6 & & & & & & & 69,0 & & 17,5 & & 32,0 \\
\hline Alimentos, bebidas y tabaco & & & & & & 56,8 & 5,0 & 28,6 & & 27,0 & & & 7,2 & & \\
\hline Madera y papel & & & & & & & 44,5 & 11,8 & 82,4 & 22,0 & & & & & \\
\hline Ind. química, goma y plástico & & & & & & & & 8,3 & & & & 94,4 & 7,4 & & \\
\hline Otras industrias & & & & & & 9,9 & & 12,2 & & & 13,6 & & & & \\
\hline Electricidad, gas y agua & & & & & 69,6 & 17,5 & 28,7 & 26,9 & & & & & 7,8 & 45,1 & 21,9 \\
\hline Construcción & & & & & 13,3 & & 8,9 & & & & & & & & \\
\hline Comercio & & & & & & & & & & & & & 7,1 & & \\
\hline Transporte y almacenaje & & & & & 8,7 & & & 6,1 & & & & & & & \\
\hline Comunicaciones & & & & & & & & & & & & & & 26,2 & 10,7 \\
\hline Servicios financieros y seguros & & & & & & & & & & & & & 28,3 & 14,5 & 13,1 \\
\hline Otros servicios & & & & & & & & & & & & & 9,5 & & \\
\hline Subtotal & 98,3 & 93,2 & 99,7 & 94,6 & 91,6 & 92,3 & 92,2 & 94,0 & 97,1 & 87,2 & 97,7 & 94,4 & 84,7 & 85,7 & 77,7 \\
\hline Total (millones de dólares) & 3375 & 8271 & 2449 & 1695 & 1030 & 264 & 478 & 988 & 77 & 495 & 193 & 964 & 15275 & 22850 & 58404 \\
\hline
\end{tabular}

Fuente: elaborado con datos del Comité de Inversiones Extranjeras.

a En virtud del Decreto Ley N No 600, Estatuto de la Inversión Extranjera, Ley de cambios internacionales. 


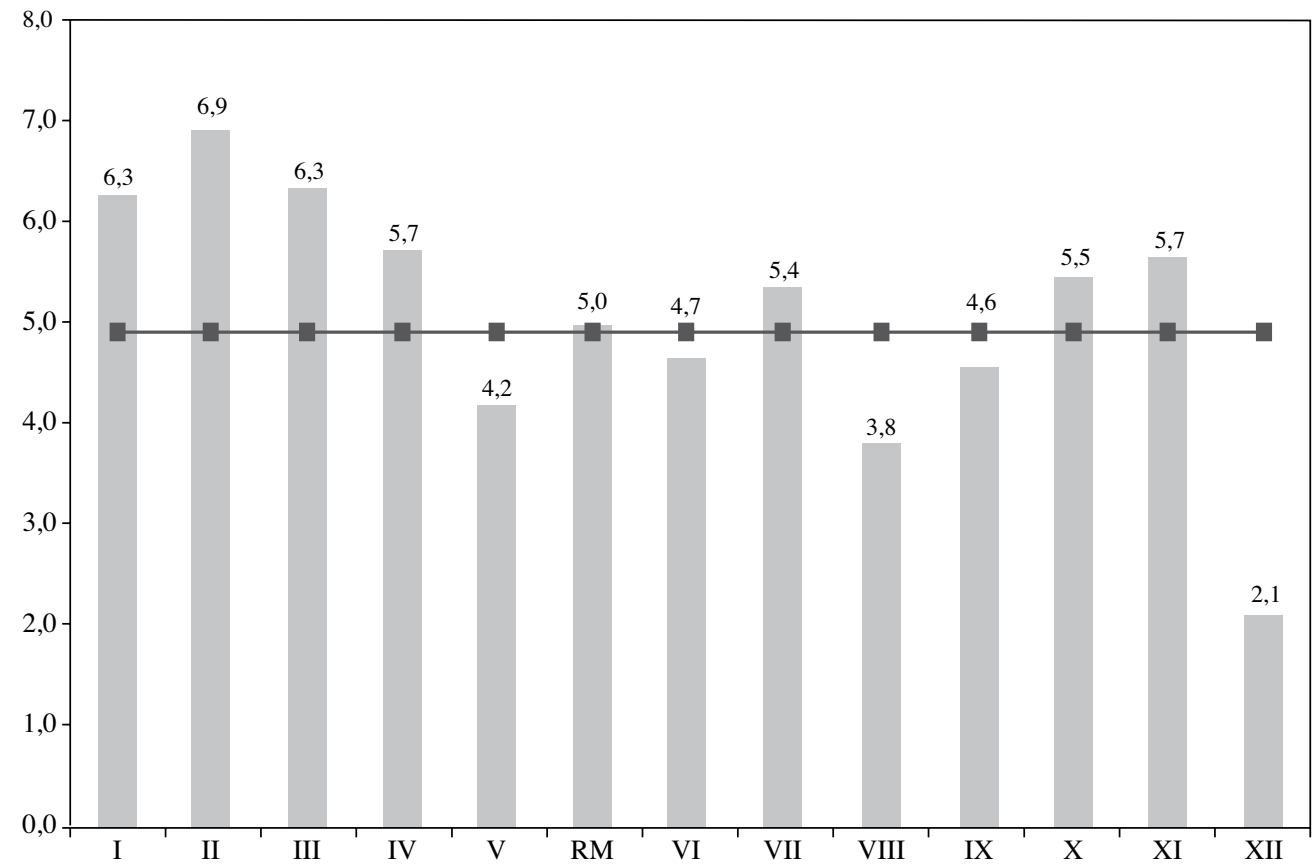

Fuente: elaboración propia con datos del MIDEPLAN y del Banco Central de Chile.

a I Región de Tarapacá; II Región de Antofagasta; III Región de Atacama; IV Región de Coquimbo; V Región de Valparaíso; VI Región de O’Higgins; VII Región del Maule; VIII Región del Bío Bío; IX Región de La Araucanía; X Región de Los Lagos; XI Región de Aysén; XII Región de Magallanes y XIII Región Metropolitana.

\section{III}

\section{Dinámica económica de las regiones, 1990-2004}

Entre 1990 y 2004 la economía chilena creció a una tasa media anual de 5\%. Este crecimiento alcanzó a las diversas regiones del país de manera altamente diferenciada. ${ }^{2}$ En efecto, un primer grupo de regiones, todas ubicadas en la zona norte, exhibieron tasas de crecimiento que superaron el 6\% (regiones de Tarapacá, Atacama y Antofagasta). En un rango intermedio, con crecimientos medios anuales de entre 5\% y 6\%, se ubicaron la Región Metropolitana, la Región de Los Lagos y las regiones de Aysén, del Maule y de Coquimbo. Crecieron bajo el promedio, entre $4 \%$ y

\footnotetext{
${ }^{2}$ La información sobre el PIB regional que elabora el Banco Central de Chile se encuentra disponible solo hasta el 2004 en términos totales y hasta el 2003 en términos sectoriales.
}

5\%, las regiones de Valparaíso, O’Higgins y La Araucanía. Y las que mostraron menor dinamismo fueron las del Bío Bío, con un promedio anual de 3,8\%, y de Magallanes, con uno de solo $2,1 \%$ (gráfico 1).

El resultado global de la economía chilena en el período 1990-2004 debe analizarse considerando su desempeño en dos etapas que reflejan situaciones internacionales bastante distintas: el antes y el después de la denominada crisis asiática que golpeó a la economía mundial en 1997. Mientras que entre 1990 y 1997 el crecimiento medio anual de Chile fue de 7\%, entre 1997 y 2004 alcanzó a solo un 3,1\%. El menor dinamismo observado a partir de 1997 se tradujo en una reducción de la tasa media de crecimiento de todas las regiones del país, especialmente en las regiones del norte y sobre 
todo en la de Atacama. La reducción también fue significativa en la Región Metropolitana, la del Maule y la de La Araucanía (gráfico 2).

Otra forma de analizar la trayectoria económica de las regiones es comparar la evolución del PIB de cada región con el crecimiento del PIB total regionalizado, obteniéndose de esta forma un indicador de las disparidades en materia de crecimiento. Las regiones que se encuentran por sobre el eje 100 (gráfico 3) son las que han ganado posición relativa y las que se ubican

GRÁFICO 2

Chile: crecimiento económico por regiones, 1990-1997 y 1997-2004ª

(Tasas de variación medias anuales)

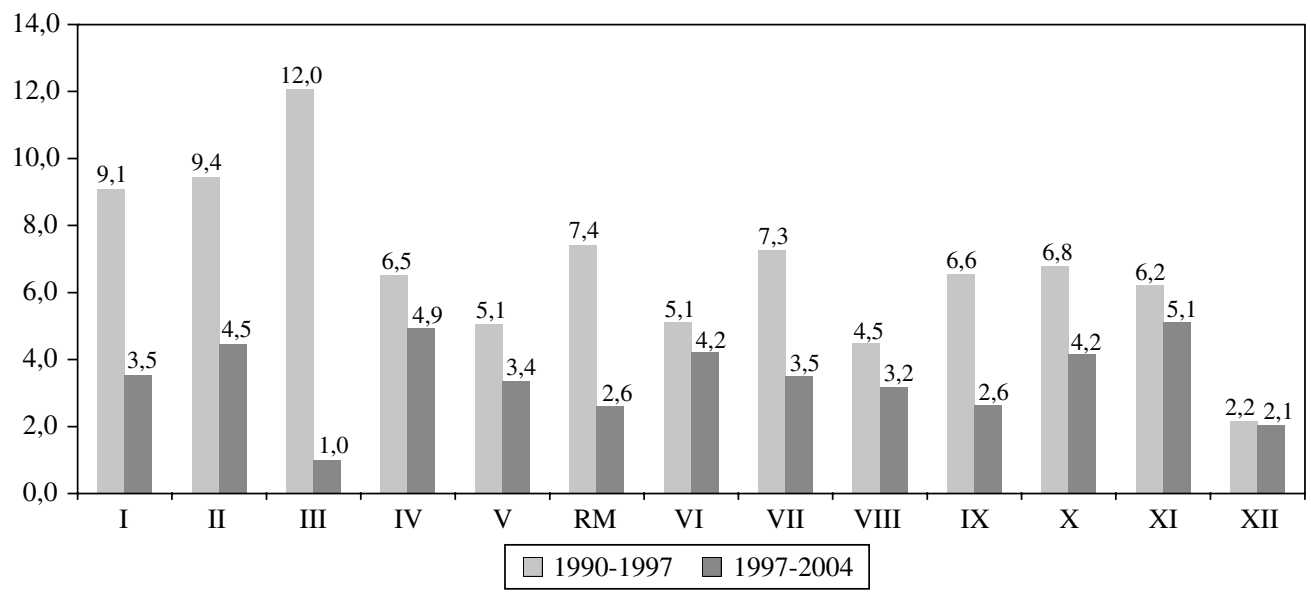

Fuente: elaboración propia con datos del MIDEPLAN y del Banco Central de Chile.

a Véanse los nombres de las regiones en la nota del gráfico 1.

GRÁFICO 3

Chile: crecimiento económico regional, 1990-2004

(Índices regionales/índice nacional, base 1990=100)

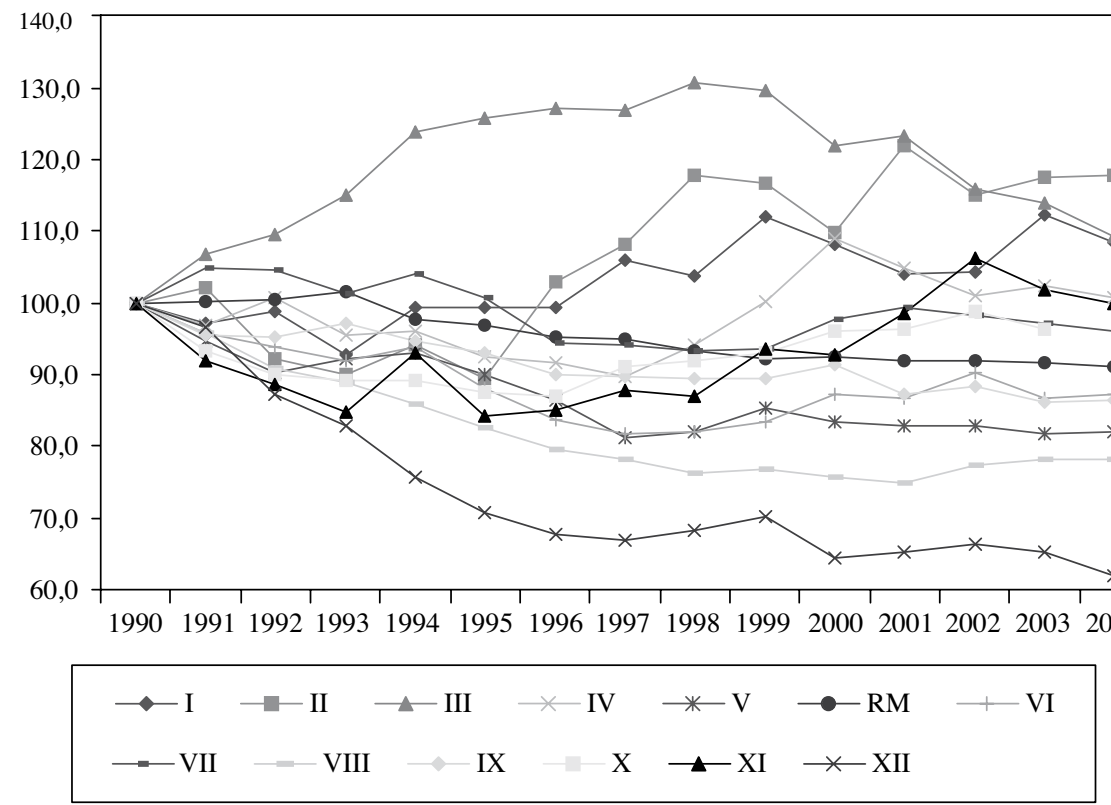

Fuente: elaboración propia con datos del MIDEPLAN y del Banco Central de Chile. 
bajo el eje han perdido posición relativa. Las regiones relativamente más rezagadas son las de Magallanes, del Bío Bío, de Valparaíso, de La Araucanía y de O’Higgins, mientras que en el caso opuesto se encuentran las de Antofagasta, Tarapacá, Atacama, Coquimbo, el Maule, Aysén y Los Lagos. Desde el año 1997 la Región Metropolitana tiende a converger hacia el promedio nacional de crecimiento.

Aunque los impactos de las distintas dinámicas de crecimiento regional no han modificado apreciablemente el patrón concentrador presente en la economía chilena, cabe destacar tres cambios importantes en la distribución del PIB regionalizado. En primer lugar, las regiones del norte han incrementado su peso relativo en el PIB total, en especial las de Antofagasta y Tarapacá. En segundo lugar, las regiones del Bío Bío y de Valparaíso, las dos más grandes después de la Región Metropolitana, han ido perdiendo peso relativo en forma sistemática y han caído bajo el $10 \%$. Finalmente, en el sur del país solo la Región de Los Lagos muestra un aumento significativo (cuadro 5).
CUADRO 5

Chile: participación en el PIB regionalizado, 1980-2004

(Porcentajes)

\begin{tabular}{lccc}
\hline Regiones & 1980-1982 & 1990-1992 & 2002-2004 \\
\cline { 2 - 4 } De Tarapacá & 3 & 3,0 & 3,5 \\
De Antofagasta & 6 & 6,1 & 7,9 \\
De Atacama & 2 & 1,6 & 1,9 \\
De Coquimbo & 2 & 2,1 & 2,4 \\
De Valparaíso & 11 & 9,7 & 9,0 \\
De O’Higgins & 47 & 48,5 & 47,8 \\
Del Maule & 5 & 4,5 & 4,5 \\
De Bío Bío & 3 & 3,7 & 3,8 \\
De La Araucanía & 12 & 11,1 & 9,7 \\
De Los Lagos & 3 & 2,8 & 2,7 \\
De Aysén & 4 & 4,5 & 5,0 \\
De Magallanes & 1 & 0,5 & 0,6 \\
R. Metropolitana & 2 & 1,9 & 1,4 \\
& & & \\
Total & 100 & 100,0 & 100,0 \\
\hline
\end{tabular}

Fuente: elaboración propia con datos del MIDEPLAN y del Banco Central de Chile.

\section{IV}

\section{Evolución de las economías regionales y clasificación según sus dinámicas de crecimiento}

Para interpretar la evolución de las economías regionales se propone clasificarlas utilizando cuatro cuadrantes (gráfico 4), que se construyen de la siguiente manera: el universo de las regiones de un país se ubica en un plano de coordenadas que permita establecer cuatro categorías sobre la base del mayor (o menor) PIB per cápita nacional y de la mayor (o menor) tasa de crecimiento del PIB per cápita regional comparado con el parámetro nacional. Las regiones se ubican a la derecha (izquierda) cuando tienen un PIB per cápita superior (inferior) al promedio nacional y están arriba (abajo) de la tasa de crecimiento nacional. El cruce de ambas dimensiones configura cuatro cuadrantes. La clasificación persigue, en primera instancia, buscar interpretaciones a lo que está sucediendo a nivel de regiones internas en los distintos países; en este sentido, el esquema de análisis utilizado probablemente plantee interrogantes frente a los cuales habrá que elaborar otra información.

Los cuatro cuadrantes tipo indicados en el gráfico 4 corresponden a regiones ganadoras, convergentes, estancadas o declinantes. i) Regiones ganadoras: dinámicas y con alto PIB per cápita. Son las que han crecido por sobre el promedio nacional y que tienen un PIB per cápita también superior al promedio nacional. Por lo tanto, son a las que les va mejor en términos económicos y se las puede considerar como las de comportamiento más exitoso frente a los procesos de globalización. Sin embargo, ser regiones ganadoras hoy día, por la dinámica de los acontecimientos económicos, no significa necesariamente serlo mañana. Para que sigan siendo ganadoras necesitarán políticas $\mathrm{y}$ actitudes muy proactivas frente al proceso de internacionalización de la economía mundial.

ii) Regiones convergentes: dinámicas y con bajo PIB per cápita. Son las que han crecido por sobre el promedio nacional y que tienen PIB per cápita inferiores al promedio nacional. El término "convergentes" indica que pese a ser más pobres o atrasadas que las demás (PIB per cápita inferior), exhiben un ritmo de crecimiento satisfactorio y están convergiendo, es decir, avanzan en el mismo sentido que las regiones 


\section{Cuadrantes de evolución económica regional}

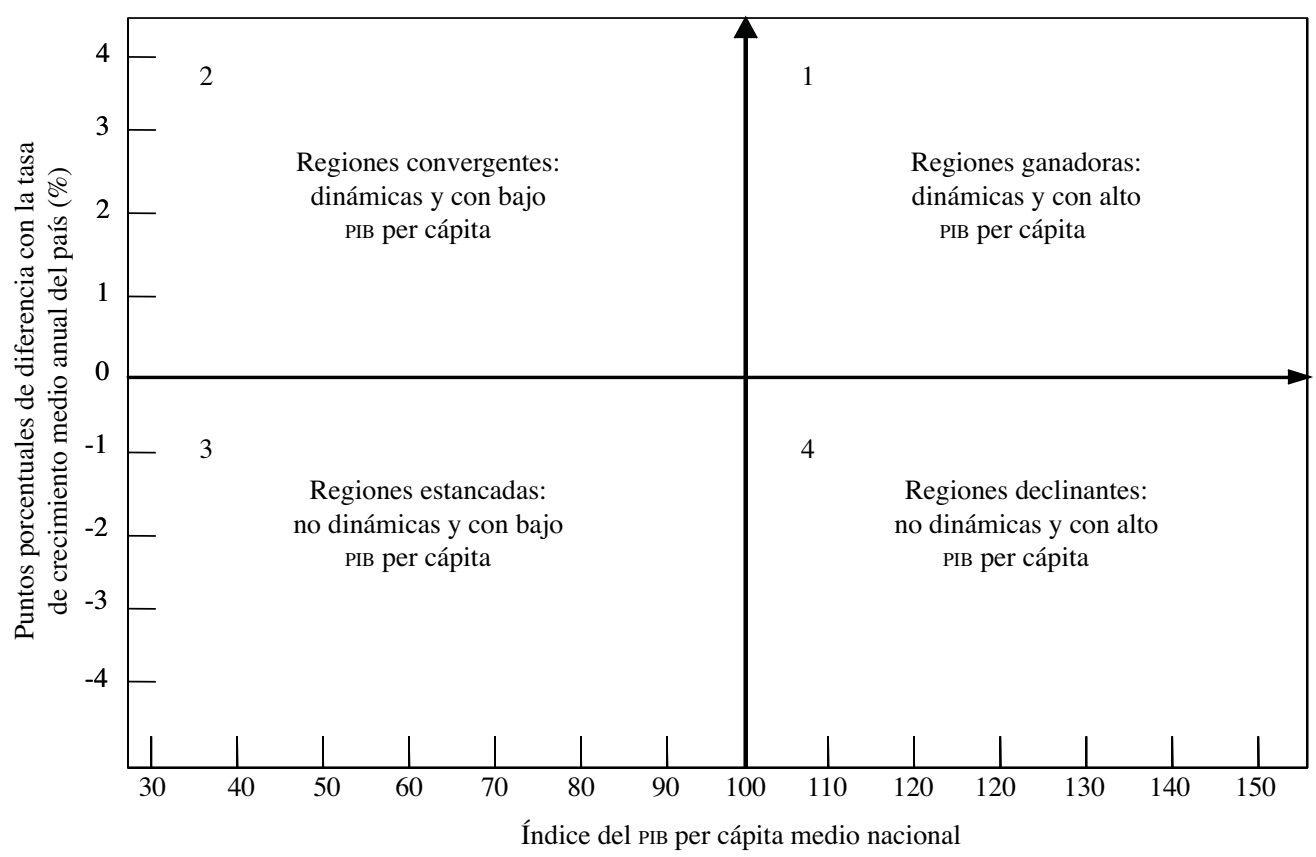

Fuente: elaboración propia.

más ricas, con miras a alcanzarlas. Son regiones ganadoras aunque aún no superan el PIB per cápita medio nacional.

iii) Regiones estancadas: no dinámicas y con bajo PIB per cápita. Son las que han crecido por debajo de la media nacional y cuyos productos per cápita también están por debajo del promedio nacional. Son "estancadas" debido a que su bajo dinamismo económico las mantiene en una situación de mayor atraso y, de no mediar acciones explícitas, su situación relativa podría tender a empeorar; por lo tanto, son consideradas perdedoras. Es posible distinguir en este grupo aquellas que han ingresado a él en periodos recientes y aquellas que secularmente han estado en él: corresponden a regiones económicamente excluidas.

iv) Regiones declinantes: no dinámicas y con alto PIB per cápita. Son las que han crecido por debajo del promedio nacional, aunque sus PIB per cápita son superiores al promedio nacional. Se supone que en el pasado les fue muy bien y alcanzaron altos PIB per cápita, pero que han caído en períodos de lento crecimiento económico que ponen en riesgo su mejor situación relativa.
Sobre la base de la información disponible, en el gráfico 5 se resume la clasificación por cuadrantes de las 13 regiones en que estaba dividido Chile hasta el año $2007 .^{3}$

Se puede avanzar en el análisis de la información disponible, utilizando en forma complementaria el método diferencial estructural, que ayuda a clasificar las diversas regiones en función de su comportamiento económico, y buscando distintas interpretaciones de tal comportamiento.

En esencia, el método diferencial estructural compara el cambio observado en una variable - en este caso el PIB- en cierto período de tiempo, tanto en cada región como en el país en su conjunto, con el cambio que se habría producido en cada una de las regiones si el PIB se hubiese comportado de idéntica manera tanto en las regiones como en el país. El gráfico 6 muestra un ordenamiento de las regiones de Chile conforme a

\footnotetext{
${ }^{3}$ Hoy las regiones de Chile son 15. En marzo y en octubre del 2007 las leyes 20.174 y 20.175 crearon respectivamente la Región de Los Ríos y la Región de Arica y Parinacota. La primera se formó con algunas provincias de la Región de Los Lagos, y la segunda con algunas provincias de la Región de Tarapacá.
} 


\section{Chile: clasificación de las regiones} por cuadrantes

\begin{tabular}{|l|l|}
\hline \multicolumn{1}{|c|}{$\begin{array}{c}\text { Cuadrante -+: } \\
\text { convergentes }\end{array}$} & \multicolumn{1}{c|}{$\begin{array}{c}\text { Cuadrante ++: } \\
\text { ganadoras }\end{array}$} \\
\hline $\begin{array}{l}\text { Región del Maule } \\
\text { Región de Los Lagos } \\
\text { Región de Coquimbo }\end{array}$ & $\begin{array}{l}\text { Región de Antofagasta } \\
\text { Región de Tarapacá } \\
\text { Región de Atacama } \\
\text { Región de Aysén }\end{array}$ \\
\hline \multicolumn{1}{|c|}{$\begin{array}{c}\text { Cuadrante --: } \\
\text { estancadas }\end{array}$} & \multicolumn{1}{c|}{$\begin{array}{c}\text { Cuadrante +-: } \\
\text { declinantes }\end{array}$} \\
\hline $\begin{array}{l}\text { Región de La Araucanía } \\
\text { Región de O'Higgins } \\
\text { Región de Valparaíso } \\
\text { Región del Bío Bío }\end{array}$ & $\begin{array}{l}\text { Región Metropolitana } \\
\text { Región de Magallanes }\end{array}$ \\
\hline
\end{tabular}

Fuente: elaboración propia.

un análisis realizado para el período 1990-2002. La diagonal que aparece en dicho gráfico distingue dos categorías de regiones: las que están por encima de la diagonal exhiben un efecto total positivo (son dinámicas), mientras que las que están por debajo de ella presentan un efecto total negativo (son lentas). Este efecto total se puede descomponer en un efecto diferencial y un efecto estructural. ${ }^{4}$

\footnotetext{
${ }^{4}$ Una explicación más detallada de cada uno de estos efectos es la siguiente:

- Efecto total: es la diferencia (positiva o negativa) entre el valor actual del PIB de una región y el valor hipotético que habría tenido ese PIB si hubiera evolucionado al mismo ritmo que el del país. Por lo tanto, un efecto positivo indica una dinámica regional mayor que la nacional.

- Efecto diferencial: es la diferencia en la evolución del PIB de cada sector regional versus el valor que el PIB habría alcanzado si el sector hubiera evolucionado a nivel regional a la misma tasa que a nivel nacional. La sumatoria de las diferencias sectoriales puede ser positiva o negativa, lo que determina el signo del efecto diferencial. Este factor explica la parte de la diferencia total que puede ser atribuida al hecho de que diferentes regiones se expanden (o contraen) a tasas también diferentes, lo que significa que una misma actividad puede mostrar un ritmo de cambio distinto a nivel de una región y a nivel del país en su conjunto.

- Efecto estructural: aritméticamente se obtiene como la diferencia entre el efecto total y el diferencial. Lo importante es que este factor explica aquella parte de la diferencia total que se atribuye al hecho de que la región esté especializada o no en actividades que a nivel nacional han mostrado un comportamiento muy diferente al promedio de toda la economía. En otras palabras, este factor explica qué parte de la diferencia (hipotética) puede ser atribuida al hecho de que la estructura regional sea diferente (o semejante) a la nacional. Por ejemplo, un efecto
}

GRÁFICO 6

Chile: clasificación de las regiones según su dinámica de crecimiento, mediante el método diferencial estructural, $1990-2002^{a}$

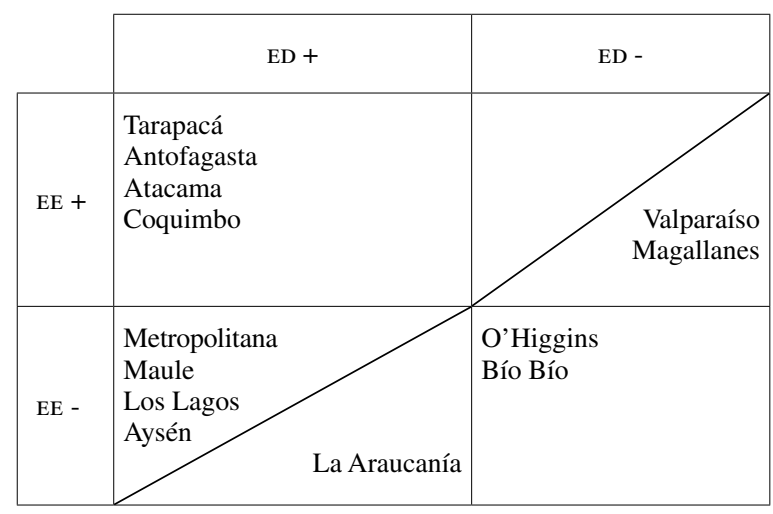

Fuente: elaboración propia.

a $\mathrm{ED}=$ efecto diferencial. $\mathrm{EE}=$ efecto estructural.

A cada una de estas situaciones corresponden, a su vez, tres alternativas. De allí resultan seis grupos de regiones:

i) Dinámicas, con buen desempeño y buena estructura: regiones que han ganado en todos los aspectos: la dinámica regional de sus sectores ha sido superior a la de esos sectores a nivel nacional, y sus estructuras productivas han estado especializadas en actividades que a nivel nacional han sido de rápido crecimiento.

ii) Dinámicas, con buen desempeño y mala estructura: regiones cuya dinámica sectorial ha sido superior al promedio nacional, pero cuyas estructuras productivas, particularmente en el año base, no estaban especializadas en sectores de rápido crecimiento.

iii) Dinámicas, con mal desempeño y buena estructura: regiones cuya dinámica regional sectorial ha estado por debajo de los promedios nacionales, pero que por estar especializadas en sectores de rápido crecimiento a nivel nacional, en ellas el efecto estructural ha compensado la menor dinámica sectorial.

positivo significaría que la región está especializada en actividades que a nivel nacional han mostrado un rápido crecimiento.

Por lo tanto, cuando se habla de una región de buen desempeño y buena estructura, lo que se quiere decir es que sus sectores económicos han crecido, en promedio, más que los mismos sectores a nivel nacional y que, en términos de estructura, está especializada en sectores que a nivel nacional han sido de rápido crecimiento. 
iv) Lentas, con mal desempeño y mala estructura: regiones que han perdido en todos los aspectos, porque el crecimiento de sus sectores a nivel regional ha sido más bajo que el crecimiento medio de ellos a nivel nacional y porque sus estructuras productivas no han estado especializadas en actividades que exhiban rápido crecimiento en el ámbito nacional.

v) Lentas, con mal desempeño y buena estructura: regiones cuya dinámica regional ha sido inferior a la dinámica media de los sectores a nivel nacional, pero que por estar especializadas en actividades de rápido crecimiento han logrado compensar en algo esta caída, aunque sin poder evitar una pérdida absoluta.

vi) Lentas, con buen desempeño y mala estructura: regiones que han exhibido una dinámica que es aceptable pero que no basta para impulsarlas por encima de los promedios nacionales, ya que están especializadas en actividades que a nivel nacional han sido poco dinámicas o de lento crecimiento.

De los dos gráficos anteriores, el gráfico 5 se basa en la evolución del PIB per cápita y el gráfico 6 en la evolución del PIB total. Si se cruza la información de uno y otro, se observa que las regiones "ganadoras" coinciden de acuerdo con ambas informaciones. Esto es, las regiones que aparecen en el cuadrante "ganadoras" en el gráfico 5 normalmente exhiben un efecto total positivo conforme al método diferencial estructural; es decir, se encuentran ubicadas por encima de la diagonal en el gráfico 6 , aun cuando pueden no mostrar los tres efectos positivos.
El gráfico 7 da cuenta de ese cruce de dos métodos de clasificación. El área gris del gráfico indica situaciones de excepción que en este caso solo afectan a la Región Metropolitana, la que aparece como declinante pero con efecto total positivo (efecto estructural positivo y efecto diferencial negativo). Esto se debe a que la Región Metropolitana sigue siendo un polo de atracción poblacional, de modo que su PIB per cápita tiene un crecimiento modesto, por debajo del promedio nacional, a pesar de que las tasas de crecimiento de su economía agregada son superiores al promedio nacional. No se trata entonces de una región declinante, sino más bien de una que tiene una buena dinámica de crecimiento y que, por lo mismo, sigue recibiendo gente. Con esta excepción, el resultado del método de cuadrantes y el del método estructural diferencial son bastante coincidentes, de modo que es posible establecer una correlación entre ambos para identificar las regiones más emblemáticas en cada uno de los cuadrantes.

Como se observa en el gráfico 7, el primer grupo incluye aquellas regiones ganadoras que, según el método diferencial estructural, muestran los tres efectos positivos, es decir, son regiones ganadoras con buen desempeño y buena estructura. En esta posición se encuentran las regiones de Antofagasta, Tarapacá y Atacama. No así la de Aysén, que pese a acusar el efecto total positivo, exhibe el efecto estructural negativo, es decir, buen desempeño sectorial y mala estructura. Esta última región no ha estado especializada en sectores dinámicos a nivel nacional, lo que no es en sí negativo, pues indica que la región está creciendo sobre la base de especializaciones de otro tipo. Tampoco es de extrañar,

GRÁFICO 7

Chile: clasificación mediante el cruce del método de cuadrantes con el método diferencial estructural, 1990-2002a

\begin{tabular}{|c|c|c|c|c|c|c|c|c|c|c|c|}
\hline \multicolumn{6}{|c|}{ Regiones convergentes } & \multicolumn{6}{|c|}{ Regiones ganadoras } \\
\hline \multicolumn{3}{|c|}{ Efecto total positivo } & \multicolumn{3}{|c|}{ Efecto total negativo } & \multicolumn{3}{|c|}{ Efecto total positivo } & \multicolumn{3}{|c|}{ Efecto total negativo } \\
\hline EE+ ED+ & EE- ED+ & $\mathrm{EE}+\mathrm{ED}-$ & EE- ED+ & EE- ED- & EE+ ED- & $\mathrm{EE}+\mathrm{ED}+$ & EE+ ED- & EE- ED+ & EE- ED+ & EE- ED- & $\mathrm{EE}+\mathrm{ED}-$ \\
\hline \multirow[t]{3}{*}{ Coquimbo } & Maule & & & & & Antofagasta & & Aysén & & & \\
\hline & Los Lagos & & & & & Tarapacá & & & & & \\
\hline & & & & & & Atacama & & & & & \\
\hline \multicolumn{6}{|c|}{ Regiones estancadas } & \multicolumn{6}{|c|}{ Regiones declinantes } \\
\hline & & & Araucanía & $\begin{array}{l}\text { O'Higgins } \\
\text { Bío Bío }\end{array}$ & Valparaíso & & & $\begin{array}{c}\text { Región } \\
\text { Metropolitana } \\
\text { (no declinante) }\end{array}$ & & & Magallanes \\
\hline
\end{tabular}

Fuente: elaboración propia.

a $\quad \mathrm{EE}=$ efecto estructural. $\mathrm{ED}=$ efecto diferencial. 
porque su estructura productiva se ha ido orientando marcadamente a actividades acuícolas y de turismo (particularmente el de intereses especiales).

En el segundo grupo - en el sentido de las manecillas del reloj- están las regiones convergentes que muestran los tres efectos positivos, es decir, son regiones convergentes con buen desempeño y buena estructura: en esta situación solo está la Región de Coquimbo. La Región del Maule y la Región de Los Lagos, aunque se hallan en este casillero, presentan una situación similar a la de la Región de Aysén, lo que también apuntaría a dinámicas económicas que siguen patrones distintos a los de sectores más dinámicos a nivel nacional.

En el tercer grupo se encuentran las regiones estancadas y que exhiben los tres efectos negativos, es decir, son regiones estancadas con mal desempeño y mala estructura. En ese casillero se encuentran la Región de O’Higgins y la del Bío Bío. Quedan por fuera, con algún efecto positivo, las de La Araucanía y de Valparaíso. En la primera, varios sectores económicos tuvieron una dinámica de crecimiento aceptable pero que no bastó para compensar su mayor especialización en actividades que a nivel nacional han sido poco dinámicas. Y en la Región de Valparaíso, su buena estructura no alcanza a compensar el mal desempeño de sus sectores económicos.

El cuarto grupo corresponde a regiones declinantes que muestran los tres efectos negativos, es decir, son declinantes con mal desempeño y mala estructura. Este caso no se observa en Chile. La Región de Magallanes exhibe al menos el efecto estructural positivo, que compensa en algo el bajo desempeño sectorial.

En el gráfico 8 se presenta una tipología de las regiones chilenas consideradas en cada cuadrante. Por cuadrante, las regiones se pueden clasificar teniendo en cuenta qué tipo de sector (primario o secundario) es más representativo, en cada una de ellas, de los cambios económicos regionales.

Vemos así que en las regiones ganadoras el crecimiento se ha debido primordialmente a actividades del sector primario, en este caso la minería y la pesca, que normalmente han significado la explotación de un recurso natural o semielaborado exportable. Entre las regiones convergentes hay algunas en las que la actividad primaria, que explica su mayor crecimiento, ha adquirido dinamismo o más valor en tiempos recientes y también está asociada a recursos naturales exportables (la Región de Coquimbo y la Región de Los Lagos). En otras el mayor impulso al crecimiento proviene de la industria manufacturera (es decir, del sector secundario): así, en la Región del Maule la actividad manufacturera está muy ligada a la industria forestal y a la de alimentos, que tienen fuertes vinculaciones con la economía mundial. Entre las regiones estancadas, en algunas predominan actividades primarias tradicionales de baja productividad, normalmente orientadas a los mercados internos y con muy pocas posibilidades de reconversión (las regiones de O'Higgins y de La Araucanía). En otras hay una tradición manufacturera reconocida que, a raíz de los procesos de liberalización y de reconstrucción productiva, ha venido perdiendo dinamismo y nivel de riqueza: es el caso de la Región de Valparaíso y también de la Región del Bío Bío, esta última afectada particularmente por el deterioro de la industria textil. Entre las regiones declinantes están aquellas que han retrocedido en sus capacidades competitivas por el agotamiento o decadencia de un sector primario: esto se observa en la Región de Magallanes respecto de la actividad asociada al petróleo y el carbón, en el cual basaba buena parte de sus expectativas de crecimiento. La Región Metropolitana, por su parte, pese a haber alcanzado estándares de crecimiento relativamente altos, se ha desindustrializado a raíz de

GRÁFICO 8

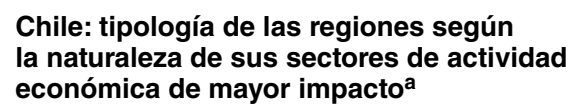

\begin{tabular}{|c|c|}
\hline $\begin{array}{l}\text { Cuadrante -+: } \\
\text { regiones convergentes }\end{array}$ & $\begin{array}{l}\text { Cuadrante }++ \text { : } \\
\text { regiones ganadoras }\end{array}$ \\
\hline $\begin{array}{c}\text { Primario emblemático } \\
\text { R. de Coquimbo }\end{array}$ & $\begin{array}{l}\text { Primarios emblemáticos } \\
\mathrm{R} \text { de Antofagasta } 250.7\end{array}$ \\
\hline $\begin{array}{c}\text { Primario } \\
\text { R. de Los Lagos } 72,5\end{array}$ & $\begin{array}{l}\text { R. de Tarapacá } 128,4 \\
\text { R. de Atacama 104,8 }\end{array}$ \\
\hline $\begin{array}{c}\text { Secundario } \\
\text { R. del Maule 64,1 }\end{array}$ & $\begin{array}{c}\text { Primario } \\
\text { R. de Aysén 100,5 }\end{array}$ \\
\hline $\begin{array}{l}\text { Cuadrante - -: } \\
\text { regiones estancadas }\end{array}$ & $\begin{array}{l}\text { Cuadrante +-: } \\
\text { regiones declinantes }\end{array}$ \\
\hline $\begin{array}{c}\text { Primario emblemático } \\
\text { R. de O'Higgins } 88,0\end{array}$ & $\begin{array}{c}\text { Primario } \\
\text { R. de Magallanes } 136,2\end{array}$ \\
\hline $\begin{array}{c}\text { Primario } \\
\text { R. de La Araucanía 47,2 }\end{array}$ & $\begin{array}{c}\text { Secundario } \\
\text { R. Metropolitana } 118,7\end{array}$ \\
\hline $\begin{array}{l}\text { Secundario emblemático } \\
\text { R. del Bío Bío } 76,1\end{array}$ & \\
\hline $\begin{array}{c}\text { Secundario } \\
\text { R. de Valparaíso } 88,5\end{array}$ & \\
\hline
\end{tabular}

Fuente: elaboración propia.

a Los números que figuran a la derecha de cada región son un índice de su posición respecto del promedio nacional (índice 100). 
cambios en las políticas nacionales de incentivos, en los procesos de apertura externa, o en ambas cosas; con esto han mermado las posibilidades de competir de sus industrias, orientadas principalmente al mercado interno. Además, como ya hemos dicho, esta región atrae a amplios contingentes de población, lo que empuja al PIB por habitante a la baja.

Las secciones siguientes analizan con más detalle cada uno de los cuadrantes y las regiones que figuran en ellos.

\section{Regiones ganadoras: dinámicas y con un alto producto interno bruto per cápita}

Estas regiones ganadoras acentúan o extienden la brecha que las separa de las regiones de menor desarrollo relativo. Es posible distinguir al menos tres situaciones que explican el alto dinamismo relativo de su PIB per cápita.

\section{Regiones de Tarapacá y Antofagasta}

Ambas están muy vinculadas a sectores de recursos mineros exportables — principalmente cobre - y su mayor dinamismo relativo corresponde justamente a esta especialización. El nivel de especialización de ambas regiones es alto, ya que los sectores indicados representan el $25,1 \%$ y el $62,7 \%$ del PIB regional respectivo. ${ }^{5}$ A la vez, desde el punto de vista del método diferencial estructural, estas regiones tienen efecto total positivo que obedece principalmente a un alto porcentaje de ganancias positivas en estos sectores de especialización (cuadro 6). Ambas regiones han aprovechado una ventaja competitiva muy explícita y marcada como es la minería, que ha atraído inversión extranjera y nacional, y han podido proyectarse al mundo a través de sus exportaciones, en un clima de apertura propiciado por la política económica nacional. Se podría decir que la globalización es oportuna y favorable para regiones que compiten básicamente a partir de una ventaja natural.

El peso de la minería del cobre se expresa en que el valor de sus exportaciones se elevó de 5 millones de dólares en 1990 a 3.500 millones de dólares en 2006 en el caso de Tarapacá, y de 2.100 millones a 17.400 millones en el caso de Antofagasta. En inversiones extranjeras directas (IED) dirigidas a la minería entre 1990 y 2006, Tarapacá acumuló 3.300 millones de dólares y Antofagasta 7.800 millones.

CUADRO 6

Chile: las regiones ganadoras y los sectores de mayor impacto

\begin{tabular}{lllrrr}
\hline Sectores & Regiones & Producto principal & $\begin{array}{c}\text { \% del PIB } \\
\text { regional }\end{array}$ & $\begin{array}{c}\text { Indicador de } \\
\text { especialización }\end{array}$ & $\begin{array}{c}\text { \% del efecto total } \\
\text { debido al sector }\end{array}$ \\
\hline \multirow{2}{*}{ Minería } & De Tarapacá & Cobre & 25,1 & 2,9 & 162,1 \\
Pesca & De Antofagasta & Cobre & 62,7 & 7,3 & 38,8 \\
Electricidad, gas y agua & De Aysén & Pesca extractiva y cultivos & 27,9 & 16,2 & 149,9 \\
\hline
\end{tabular}

Fuente: elaboración propia.

\footnotetext{
${ }^{5}$ El cuadro 6 incluye un indicador de especialización que en técnicas de análisis regional se denomina cociente de localización. Se dice que cuando este valor es mayor que uno la región está especializada en ese sector. Este indicador se obtiene como el cociente entre el porcentaje que el PIB de un sector representa en la región y el porcentaje que ese mismo sector representa
}

a nivel nacional. Por ejemplo, en el caso de Aysén el valor del cociente de 16,2 indica que la actividad económica de la pesca en esa región es 16,2 veces mayor que la actividad de ese mismo sector a nivel nacional. Este es un valor extraordinariamente alto que denota, por lo tanto, un muy elevado nivel de especialización en este sector. 
La dinámica social de ambas regiones ha sido superior a la del promedio del país. Antofagasta, en particular, exhibió en 2003 la menor proporción de población en condiciones de pobreza (un 11,2\%). Asimismo, los ingresos de los hogares se han ubicado en torno al promedio nacional o por encima de él. En otros indicadores de desempeño social, como el promedio de escolaridad, ambas regiones también superan el promedio del país.

Sin embargo, habrá que ver si el tramado productivo y de servicios de estas regiones es capaz de densificarse y diversificarse a la par con el ritmo de desarrollo de la minería, para que los efectos de esta actividad se hagan sentir con más fuerza aún en la economía de las dos regiones consideradas. Hoy en día ellas son ganadoras, pero está por verse si serán capaces de construir ventajas competitivas avanzadas que les permitan asegurar un desarrollo sustentable en el tiempo. Cabe recordar que, durante la crisis asiática, fueron estas regiones las que mostraron los mayores incrementos en las tasas de desempleo, hecho que plantea la necesidad de una mayor diversificación productiva.

\section{Región de Aysén}

La Región de Aysén crece con pujanza gracias a un mayor dinamismo de la pesca, sector que representa cerca de un 30\% del PIB de la región y muestra un cociente de especialización muy elevado, de 16,2. Cerca del $80 \%$ del crecimiento total de la región entre 1990 y 2002 puede atribuirse al sector pesquero, que está fuertemente orientado a los mercados externos. Las exportaciones de alimentos, sobre todo productos de la pesca, subieron de 51 millones de dólares en 1990 a cerca de 270 millones en el 2006.

En años recientes esta región está siendo uno de los destinos principales de la expansión geográfica de la industria salmonera, que hoy ocupa el segundo lugar en la canasta exportadora del país. En este caso, igual que en la Región de Los Lagos, la actividad salmonera enfrenta importantes desafíos relacionados con su impacto medioambiental, que podría contraponerse a estrategias e iniciativas de desarrollo turístico que comienzan a explorarse y a ponerse en marcha en la región.

El dinamismo económico regional, unido a una fuerte inyección de recursos públicos por habitante, han mejorado las condiciones sociales, lo que se ha traducido en un incremento de los ingresos de los hogares y una baja de la proporción de habitantes en condición de pobreza. No obstante, permanecen por debajo del promedio nacional algunos indicadores sociales, como el promedio de escolaridad.

\section{Región de Atacama}

Esta región es predominantemente minera, al igual que las de Tarapacá y de Antofagasta. En ella el peso de la actividad minera se ha hecho sentir de manera indirecta, ya que el sector que más ha contribuido al crecimiento regional ha sido el de electricidad, gas y agua. El aporte mayor lo ha hecho la electricidad, en particular por la construcción de una nueva planta generadora cuyos clientes principales son precisamente las mayores empresas mineras de la región.

La región experimentó su mayor dinamismo en la primera mitad de los años 1990, cuando exhibió el mayor crecimiento medio en el país (12\%), debido en gran medida a megaproyectos cupríferos como La Candelaria, y a los grandes proyectos eléctricos. También expandió significativamente las actividades frutícolas de exportación, principalmente uvas, que han contribuido a sostener una economía sujeta a las fluctuaciones de los mercados mundiales de productos mineros. Esas fluctuaciones hicieron que a partir de la segunda mitad de los años 1990 un crecimiento medio anual en torno al $12 \%$ disminuyera a solo $1 \%$. En años recientes ha retornado el interés por desarrollar proyectos mineros, en particular de oro y plata, lo que ha significado una importante afluencia de inversiones extranjeras. Entre los proyectos de esta índole el más grande es el de Pascua Lama.

La volatilidad del desarrollo minero en la región ha contribuido a que las condiciones sociales muestren importantes oscilaciones. Así, entre 1996 y 1998 la Región de Atacama fue la única del país en que la pobreza aumentó, y en 2003 aún estaba entre las cuatro regiones chilenas con mayor porcentaje de pobres.

Como conclusión, puede sostenerse que en este grupo de regiones la inserción externa basada en el aprovechamiento de recursos naturales mineros y pesqueros ha influido positivamente en sus posibilidades de desarrollo económico y social. No obstante, para que ese desarrollo sea sostenible es preciso fortalecer el esfuerzo de diversificación productiva y de encadenamientos sectoriales — sobre todo en el caso de la minería, por tratarse de recursos no renovables en el largo plazo-y extremar la preocupación por los riesgos ambientales asociados a estas actividades. 


\section{VI}

\section{Regiones convergentes: dinámicas}

\section{y con bajo producto interno bruto per cápita}

Estas regiones, si bien presentan un PIB per cápita inferior al del país en su conjunto, se encuentran en una situación expectante, pues podrían reducir la distancia que las separa de las más avanzadas si su mayor dinamismo relativo se sostuviera en el tiempo.

En el cuadro 7 se presenta información resumida sobre la Región de Coquimbo, la Región de Los Lagos y la del Maule, identificando también tres situaciones que explican su mayor dinamismo económico.

\section{Región de Coquimbo}

Esta región se ha sumado en años recientes al auge cuprífero surgido a partir del desarrollo del proyecto minero Los Pelambres. Para apreciar la importancia de la minería en la región hay que considerar que genera el $25,1 \%$ del PIB regional y que su cociente de especialización es cercano a 3. Por otra parte, el aporte de la minería al efecto total alcanza a un elevado 87\%. Entre 1990 y el 2006 el sector minero atrajo casi el $95 \%$ de la afluencia de IED a la región, que alcanzó un total acumulado de cerca de 1.700 millones y representó casi el $70 \%$ del valor total de las exportaciones regionales.

Pese al incremento de la especialización en actividades mineras, la Región de Coquimbo exhibe más diversificación económica que las regiones de Tarapacá, de Antofagasta y de Atacama. Cabe mencionar en particular la fruticultura de exportación, que acrecentó el valor de sus exportaciones de 26 millones de dólares en 1990 a cerca de 220 millones en el 2006.

Por otra parte, también se ha expandido un conjunto de actividades económicas vinculadas al turismo, sector de creciente importancia en la economía global. Esa expansión se ha reflejado en tasas de crecimiento medias de actividades como las de transporte y comunicaciones y las de comercio, restaurantes y hoteles, que son superiores a las tasas medias de la región.

El buen desempeño económico descrito explica en parte el significativo mejoramiento de las condiciones sociales. En efecto, entre 1990 y 2003 la Región de Coquimbo logró la mayor reducción de la pobreza a nivel nacional — de un $45,3 \%$ a un $21,5 \%$ - y vio mejorar los ingresos de los hogares: de ser $25 \%$ más bajos que el promedio nacional, pasaron a ser $16 \%$ más bajos.

\section{Región de Los Lagos}

Esta región está fuertemente vinculada al sector pesquero y parece haber aprovechado una ventaja comparativa interesante en sectores primarios: está altamente especializada en pesca, lo que se refleja en un cociente de especialización de 10,8. Comparada con las regiones mineras, sus sectores de especialización tienen un peso menor $(18,6 \%)$ en el PIB regional.

La actividad pesquera se encuentra asociada sobre todo a la explotación del salmón a escala industrial, lo que ha transformado significativamente la economía regional. En efecto, la pesca pasó de representar el 4,3\% del PIB regional en 1990 a representar casi el 19\% en el 2002. A la vez, el sector silvoagropecuario disminuyó su participación en el PIB regional del 17\% al 10,6\%. Los efectos de este cambio se han hecho sentir en la estructura productiva, el mercado de trabajo y el capital humano de la zona.

CUADRO 7

Chile: las regiones convergentes y los sectores de mayor impacto

\begin{tabular}{|c|c|c|c|c|c|}
\hline Sectores & Regiones & Producto principal & $\%$ del PIB regional & $\begin{array}{l}\text { Cociente de } \\
\text { especialización }\end{array}$ & $\begin{array}{l}\% \text { del efecto total } \\
\text { debido al sector }\end{array}$ \\
\hline Minería & De Coquimbo & Cobre & 25,1 & 2,9 & 87,0 \\
\hline Pesca & De Los Lagos & Pesca extractiva y cultivos & 18,6 & 10,8 & 170,1 \\
\hline Industria & Del Maule & Celulosa & 20,5 & 1,2 & 110,1 \\
\hline
\end{tabular}

Fuente: elaboración propia. 
La implantación de la industria salmonera en Chile es una experiencia digna de estudio por la importancia económica que reviste dicha actividad, por la rapidez del ciclo de aprendizaje de un proceso de producción acuícola masiva que no existía en el país, por la forma en que se ha integrado a la globalización y porque se ha desarrollado desde sus inicios como un sistema productivo incorporado a la región. La salmonicultura, tal como se ha implantado en la Región de Los Lagos, constituye lo que la literatura especializada denomina un cluster, es decir, una aglomeración productiva de empresas que desarrollan ciertas ventajas competitivas para mantener una posición de mercado a nivel mundial. ${ }^{6}$

Las exportaciones de salmón, mayoritariamente asociadas a esta región, pasaron de 38 millones de dólares en 1989 a 1.721 millones de dólares en 2005, llegando a representar el 4,4\% de las exportaciones del país en este último año. Prácticamente toda la producción chilena de salmón y trucha en cautiverio se destina a los mercados externos y, contrariamente a lo que se podría pensar y a lo que ha pasado con otras actividades que explotan recursos naturales, el cultivo del salmón en Chile ha constituido un tema de interés por la trayectoria de aprendizaje tecnológico que ha seguido su producción en gran escala, lo que es condición esencial para desarrollar capacidades competitivas, particularmente a nivel regional.

\section{Región del Maule}

Esta región ha crecido fuertemente gracias a un mayor dinamismo de la industria manufacturera y de la actividad silvoagropecuaria, dos sectores que incrementaron su participación en el PIB regional en el período 1990-2002. En ambos ha influido la orientación hacia los mercados externos. En el sector silvoagropecuario, lo más importante ha sido el in-

${ }^{6}$ Véase Muñoz (2008) y Montero (2004). cremento del valor de las exportaciones de fruta, de poco menos de 40 millones de dólares en 1990 a 217 millones en el 2006. En la industria manufacturera el mayor dinamismo se observa en la celulosa y los vinos: entre 1990 y el 2006 el valor exportado de la celulosa subió de 72 millones a 270 millones, y el de los vinos de 4 millones a 212 millones. El caso de la industria del vino constituye tal vez el fenómeno más interesante, dadas sus mayores potencialidades de encadenamientos productivos y su mayor capacidad generadora de procesos de innovación. Estas ventajas parecen influir menos en la producción de celulosa, cuyos efectos de arrastre tienden a ser menores; sin embargo, en 1990-2006 esta industria recibió la mayor parte de las corrientes de IED: 212 millones de dólares acumulados que representan $45 \%$ del total en la región.

Pese a su gran dinamismo económico, la Región de Los Lagos sigue exhibiendo un relativo rezago en su situación social. Aun cuando entre 1990 y el 2003 la pobreza bajó de $43 \%$ a $23,1 \%$, el ingreso medio de los hogares decreció: fue $30 \%$ inferior al promedio nacional en 2003, habiendo sido $15 \%$ inferior en 1990.

Asimismo, el incremento medio registrado en la escolaridad de la población aún está por debajo del promedio nacional. La escolaridad media nacional subió de 9 a 10,2 años entre 1990 y el 2003, mientras que el promedio de la región solo aumentó de 7,5 a 8,7 años.

En conclusión, en este grupo se ubican regiones que han iniciado interesantes procesos de crecimiento asociados a cierto tipo de reconversiones productivas recientes. En algunos casos, gracias a la revolución tecnológica y de las comunicaciones (base de la nueva forma de globalización), han comenzado a aprovechar ventajas comparativas que estaban latentes, como una base económica principalmente exportadora de productos primarios o bien recursos locales a partir de los cuales pueden agregar valor a sus procesos productivos. Se las podría tipificar entonces como regiones potencialmente ganadoras que, enfrentadas a la globalización, han sacado partido de recursos locales latentes. 


\section{VII}

\section{Regiones estancadas: no dinámicas y con bajo PIB per cápita}

En este grupo se ubican las regiones consideradas perdedoras, porque además de tener un PIB per cápita inferior al promedio nacional, se caracterizan por un débil crecimiento económico (cuadro 8). De mantenerse la tendencia, se acentuará su condición de rezago, distanciándose aún más de las regiones con mayores avances.

\section{Región de La Araucanía}

Esta región, que estaba altamente especializada en el sector silvoagropecuario, ha experimentado un retroceso importante de esta actividad económica, que en general muestra una escasa vinculación con el desarrollo exportador y se orienta más bien al mercado interno. Por lo tanto, ha debido encarar la presión de productos importados a partir de una posición competitiva muy débil.

Lo anterior se ha traducido en una pérdida importante de participación del sector silvoagropecuario en el PIB regional y un retroceso en su cociente de especialización, lo que significa que la región ya no se dedica en especial a esa actividad. En efecto, su participación en el PIB regional entre principios de los años 1990 y las últimas mediciones descendió de $20 \%$ a cerca de $15 \%$.

A nivel agregado, el PIB de la región y su productividad por habitante son más de 50\% inferiores a los promedios nacionales respectivos.

En cuanto a inserción externa, la región casi no registra afluencia de IED en las últimas décadas y sus niveles de exportación — junto con los de la Región de Aysén- son los menores del país. En años recientes esos niveles se han elevado, principalmente gracias al establecimiento de una planta de celulosa que produce casi el $70 \%$ del total exportado.

La débil situación económica regional tiene como complemento una precaria situación social. Sin embargo, como el resto de las regiones, ha logrado un progreso significativo en los últimos 15 años, expresado, por ejemplo, en menos mortalidad infantil y en un marcado incremento del promedio de años de escolaridad. En estos aspectos la región exhibe los avances más rápidos del país, aunque todavía ocupa los últimos lugares en un amplio conjunto de variables sociales. A modo de ejemplo, en el 2003 los ingresos medios de los hogares se encontraban un $30 \%$ por debajo del promedio nacional y cerca de un tercio de la población permanecía en condición de pobreza.

\section{Región de O’Higgins}

Esta región se ha visto afectada por la pérdida de competitividad de la minería. En el mineral de cobre El Teniente, una división de la empresa estatal Corporación Nacional del Cobre de Chile (CODELCO), la productividad ha descendido en los últimos años en comparación con la del resto de la industria cuprífera pública y privada. Como se observa en el cuadro 8 , la

CUADRO 8

Chile: las regiones perdedoras (estancadas)

y sus sectores de mayor impacto negativo

\begin{tabular}{|c|c|c|c|c|c|c|c|c|c|c|c|c|}
\hline \multirow[t]{2}{*}{ Regiones } & $\begin{array}{c}\% \\
\text { del PIB } \\
\text { regional }\end{array}$ & $\begin{array}{c}\text { Cociente } \\
\text { de especia- } \\
\text { lización }\end{array}$ & $\begin{array}{c}\% \text { de pérdida } \\
\text { del efecto total } \\
\text { debido al sector }\end{array}$ & $\begin{array}{c}\% \\
\text { del PIB } \\
\text { regional }\end{array}$ & $\begin{array}{l}\text { Cociente } \\
\text { Especia- } \\
\text { lización }\end{array}$ & $\begin{array}{c}\% \text { de pérdida } \\
\text { del efecto total } \\
\text { debido al sector }\end{array}$ & $\begin{array}{c}\% \\
\text { del PIB } \\
\text { regional }\end{array}$ & $\begin{array}{l}\text { Cociente } \\
\text { de especia- } \\
\text { lización }\end{array}$ & $\begin{array}{c}\% \text { de pérdida } \\
\text { del efecto total } \\
\text { debido al sector }\end{array}$ & $\begin{array}{c}\% \\
\text { del PIB } \\
\text { regional }\end{array}$ & $\begin{array}{l}\text { Cociente } \\
\text { de especia- } \\
\text { lización }\end{array}$ & $\begin{array}{c}\% \text { de } \\
\text { pérdida } \\
\text { del efecto } \\
\text { total debido } \\
\text { al sector }\end{array}$ \\
\hline & \multicolumn{3}{|c|}{ Sector silvoagropecuario } & \multicolumn{3}{|c|}{ Pesca } & \multicolumn{3}{|c|}{ Minería } & \multicolumn{3}{|c|}{ Industria } \\
\hline De Valparaíso & & & & 0,2 & 0,1 & 17,6 & 3,9 & 0,5 & 30,1 & 22,7 & 1,3 & 10,8 \\
\hline De 0’Higgins & & & & & & & 10,7 & 1,2 & 618,9 & 16,2 & 0,9 & \\
\hline Del Bío Bío & 6,7 & 1,4 & 16,8 & 2,6 & 1,5 & 12,9 & 0,2 & 0,0 & 9,0 & 30,5 & 1,7 & 11,5 \\
\hline De La Araucanía & 15,2 & 3,1 & 96,0 & & & & & & & & & \\
\hline
\end{tabular}

Fuente: elaboración propia. 
proporción de pérdida del efecto total debido al sector asciende a casi $620 \%$.

El efecto agregado sobre el desempeño económico de la región ha implicado niveles de PIB por habitante y de productividad por ocupado que se ubican, en promedio, alrededor de $15 \%$ por debajo del promedio nacional.

Este efecto contrarresta con creces ciertas señales positivas observadas en algunas actividades agropecuarias y agroindustriales orientadas principalmente a la exportación, como la frutícola y vinícola. Entre 1990 y 2005 estas actividades elevaron marcadamente el valor de sus exportaciones, que pasaron de 85 millones de dólares a 400 millones en el caso de las frutas y de 3 millones de dólares a 161 millones, en el caso de la industria de bebidas alcohólicas.

En cuanto a las condiciones sociales, han mejorado también en la región los principales indicadores sociales analizados. Entre 1990 y el 2003 la pobreza se redujo de un $41 \%$ a un $19 \%$, el promedio de escolaridad aumentó de 8 años a 9,1 años y la mortalidad infantil cayó casi un $50 \%$. Sin embargo, como el crecimiento de los ingresos medios de los hogares fue inferior al promedio nacional, estos retrocedieron en términos relativos, bajando de un $76,3 \%$ del promedio nacional a un $68,1 \%$.

\section{Región de Valparaíso}

En esta región, la de mayor desarrollo relativo después de la Región Metropolitana, la mayoría de los sectores exhiben efectos negativos. A esto han contribuido especialmente la minería, la pesca, la industria manufacturera y la electricidad, gas y agua.

La Región de Valparaíso, al igual que la del Bío Bío, ha encontrado dificultades para insertarse con éxito en el modelo exportador. La participación del sector industrial en el PIB regional, que había tenido gran relevancia en el pasado, ha perdido posiciones relativas, y descendió de $25 \%$ en 1990 a $22 \%$ en el 2003.

La llegada de IED ha sido escasa, salvo por la entrada en 1999 de cerca de 500 millones de dólares destinados a empresas sanitarias. Las exportaciones regionales mostraron ritmos de crecimiento inferiores al promedio nacional hasta antes del auge del precio del cobre en los mercados internacionales.

Aun cuando su situación económica ubique a esta región entre las estancadas, su situación social muestra mejoras importantes en el período analizado. Entre 1990 y el 2003 la pobreza se redujo de 43,2\% a $19,4 \%$, la mortalidad infantil bajó $42 \%$ y el promedio de escolaridad subió de 9,3 a 10,3 años. Pero, al igual que la Región de O'Higgins, los ingresos de los hogares crecieron menos que el promedio nacional, lo que implicó descender desde 82,3\% de ese promedio en 1990 a $76,2 \%$ en el 2003.

\section{Región del Bío Bío}

Esta región constituye un caso especial, ya que en ella todos los sectores arrojan un resultado negativo según el método diferencial estructural. Su economía está bastante diversificada, con varios sectores de especialización, pero su dinamismo económico ha sido bajo y hubo pérdidas de PIB regional en todos los sectores de actividad económica en el período 1990-2002. La productividad creció un escaso $1,7 \%$ anual, cifra muy inferior al incremento medio nacional, lo que hizo que se situara $25 \%$ por debajo de ese promedio en el 2001. Las exportaciones regionales, en cambio, mostraron un gran dinamismo: se expandieron a una tasa media anual de $9 \%$ entre 1990 y 2000, lo que llevó a que en el 2000 representaran 14\% del total nacional exportado. La inversión extranjera, si bien en términos de volumen acumulado para el período 1990-2000 parece significativa (288 dólares per cápita), está muy por debajo de la recibida por otras regiones y muy lejos del promedio nacional per cápita para ese período (2.513 dólares). Algo similar ocurrió con la inversión pública que, a pesar de haber crecido en forma importante en el período 1994-2004, sigue siendo menor que el promedio nacional per cápita.

Los ingresos de los hogares también crecieron a una tasa inferior al promedio nacional y se situaron en el 2003 un $28 \%$ por debajo. La pobreza, por otra parte, pese a haber disminuido de $47,5 \%$ a $28 \%$ entre 1990 y el 2003, siguió siendo muy superior al promedio nacional; la disminución observada puede haberse debido en parte a un gasto social sectorial que creció mucho más que en el resto de las regiones analizadas. Otros indicadores sociales tampoco se vieron muy favorables. En definitiva, podría decirse que la región vivía una contradicción básica que se tradujo en bajo crecimiento económico y fuerte expansión exportadora, con escasa mejoría de sus indicadores sociales.

Resumiendo, dentro del grupo de regiones estancadas se observaban dos situaciones características:

i) La de regiones con estructuras industriales que probablemente habían sido muy protegidas, con actividad económica en constante retroceso, incapaces de reconvertir su aparato productivo y atemorizadas por la apertura y la globalización, aunque dentro de ellas coexistían espacios locales que podían constituir interesantes ámbitos de cambio e innovación; en síntesis, regiones perdedoras que 
se han desindustrializado y no han sido capaces de reconvertir sus economías locales.

ii) La de regiones agrícolas tradicionales que normalmente han estado rezagadas, algunas de ellas con mucha presencia de poblaciones indígenas que demandan del Estado políticas públicas explíci- tas destinadas a atenuar su deterioro, así como programas de recuperación específicos para cada situación concreta. Estas regiones pueden clasificarse como perdedoras, con economías rurales de baja productividad y escaso capital humano, que no han logrado insertarse en la economía global.

\section{VIII}

\section{Regiones declinantes: no dinámicas y con alto PIB per cápita}

En este grupo se ubican aquellas regiones que tienen una situación privilegiada en cuanto a PIB per cápita, pero exhiben un lento crecimiento, que de mantenerse las hará ir perdiendo posiciones relativas y acercándose a las regiones de menor desarrollo. Son, por lo tanto, regiones cuyas capacidades competitivas están retrocediendo y que pueden demandar importantes esfuerzos de reactivación (cuadro 9).

\section{Región de Magallanes}

Esta región, con una estructura económica especializada en pesca, minería y más recientemente en la actividad industrial, tuvo un crecimiento económico muy limitado en el período 1990-2002. La causa fue en buena medida la pérdida de dinamismo de la minería, particularmente asociada a la explotación de hidrocarburos que en la región han caído en un acentuado proceso de agotamiento. Sin embargo, en términos per cápita, sus exportaciones, que representan aproximadamente el 2,5\% de las exportaciones totales del país, han crecido de manera sistemática muy por encima del promedio nacional.
Asimismo, en el período 1990-2000 la IED per cápita superó con creces los promedios nacionales pertinentes, y estuvo muy concentrada en el sector químico (específicamente en el metanol). Algo similar ocurrió con la inversión pública que, en términos per cápita, fue 2,5 veces mayor que el promedio nacional. Esto no es de extrañar, ya que por hallarse en una zona extrema del país esta región disfruta de granjerías especiales.

Los ingresos de los hogares también se mantuvieron por sobre los promedios nacionales, al igual que el gasto social y otros indicadores sociales. En el período 1990-2003 la disminución de la pobreza fue la mayor del país. La tasa de pobreza cayó de $30 \%$ a tan solo $12,3 \%$ de la población, transformándose en la más baja del país. Es paradójico que en esta región, que había experimentado una notable declinación económica, los indicadores sociales se hayan mantenido o hayan mejorado notablemente, situación que contrasta con la de regiones que han crecido sostenidamente. La explicación está seguramente en las políticas públicas explícitas que impulsan a esta región extrema del sur de Chile.

CUADRO 9

Chile: las regiones declinantes y sus sectores

de mayor impacto negativo

\begin{tabular}{|c|c|c|c|c|c|c|c|c|c|}
\hline \multirow[t]{2}{*}{ Regiones } & $\begin{array}{l}\% \text { del PIB } \\
\text { regional }\end{array}$ & $\begin{array}{l}\text { Cociente } \\
\text { de especia- } \\
\text { lización }\end{array}$ & $\begin{array}{c}\% \text { de pérdida } \\
\text { del efecto total } \\
\text { debido al sector }\end{array}$ & $\begin{array}{l}\% \text { del PIB } \\
\text { regional }\end{array}$ & $\begin{array}{l}\text { Cociente } \\
\text { de especia- } \\
\text { lización }\end{array}$ & $\begin{array}{c}\% \text { de pérdida } \\
\text { del efecto total } \\
\text { debido al sector }\end{array}$ & $\begin{array}{l}\% \text { del PIB } \\
\text { regional }\end{array}$ & $\begin{array}{l}\text { Cociente } \\
\text { de especia- } \\
\text { lización }\end{array}$ & $\begin{array}{l}\% \text { de pérdida } \\
\text { del efecto total } \\
\text { debido al sector }\end{array}$ \\
\hline & \multicolumn{3}{|c|}{ Minería } & \multicolumn{3}{|c|}{ Industria } & \multicolumn{3}{|c|}{ Construcción } \\
\hline De Magallanes & 9,75 & 5,7 & 93,0 & & & & & & \\
\hline Metropolitana & & & & 18,4 & 1,0 & 303,5 & 7,2 & 0,8 & 289,4 \\
\hline
\end{tabular}

Fuente: elaboración propia. 
En resumen, la Región de Magallanes ha perdido dinamismo por el agotamiento de ciertos recursos naturales. Se observa en ella una pérdida de ventajas comparativas, que puede ser permanente o pasajera, conforme a la capacidad de impulsar nuevas actividades económicas locales.

\section{Región Metropolitana}

La inclusión de la Región Metropolitana en el grupo de regiones estancadas merece ciertas consideraciones especiales, por ser la región del país que concentra la mayor proporción de la población y de la actividad económica.

Si se aplica el método diferencial estructural, la Región Metropolitana muestra un retroceso relativo importante en ciertos sectores mayoritariamente orientados al mercado interno, como la construcción y la industria manufacturera. Ese retroceso se ve contrarrestado por significativas ganancias en sectores terciarios que son clave en el contexto de la globalización, como los servicios financieros y los de transporte y comunicaciones. Parte del resultado negativo observado en la construcción y la

\section{IX}

\section{Conclusiones}

Del análisis e información presentados se desprende que las regiones a las que les está yendo bien en Chile son aquellas que han podido insertarse satisfactoriamente en la economía mundial, ya sea a través de sus recursos naturales renovables o no renovables, a través de procesos exportadores asociados a una industria manufacturera mayormente liviana o a través de centros metropolitanos articulados con la economía mundial en la provisión de servicios financieros y comerciales.

En todas estas situaciones ha prevalecido la política de inserción macroeconómica delineada, que se ha convertido en un marco de referencia objetivo para cada región. Esta política ha favorecido fuertemente a algunas, al menos en materia de crecimiento, y ha afectado desfavorablemente a otras, dependiendo de sus propias capacidades de inserción internacional.

Cabe decir entonces que en ninguno de los casos exitosos de crecimiento regional se advierte una política explícita y deliberada de desarrollo regional que haya sido orientada desde el Estado. Que a una región le vaya bien no se debe a que el Estado haya propiciado políticas manufactura puede atribuirse al hecho de que la crisis asiática de 1997-1999 impactó con mayor fuerza a esos sectores en la región.

No obstante, en el periodo 1990-2006 fue la región que recibió más IED: 15.300 millones de dólares (excluido el componente multirregional), es decir, casi un tercio de la afluencia total de IED al país en el período indicado. Estas corrientes de IED se orientaron principalmente a actividades terciarias.

Por lo demás, la Región Metropolitana también ha intensificado su desarrollo exportador y en el trienio 2003-2005 ocupó el segundo lugar entre las regiones chilenas con mayores montos exportados (la Región de Antofagasta ocupó el primero). Asimismo, exhibe una canasta exportadora más diversificada que incluye productos con mayor elaboración y, por lo tanto, con más valor agregado.

En cuanto a las condiciones sociales, en el 2003 la región mostró uno de los más bajos porcentajes de pobreza del país $(13,1 \%)$ y los ingresos de los hogares fueron $34 \%$ superiores al promedio nacional, cifra que había sido solo de 18\% en 1990.

de desarrollo regional que hayan desembocado en esa situación. Tampoco parece haber políticas explícitas de corrección de disparidades, de naturaleza compensatoria y de claro corte regional, que atiendan a regiones deprimidas que no presentan síntomas de activación ni en el corto ni en el mediano plazo.

Por lo tanto, una conclusión fundamental, que no deja de traslucir cierta frustración, es que en las dos últimas décadas no parece haber habido en Chile políticas explícitas de desarrollo regional, por lo menos a escala nacional. No obstante, el avance generalizado, aunque dispar, de las condiciones económicas y sociales de las regiones chilenas puede vincularse a un conjunto de políticas sectoriales aplicadas en años recientes -en materias como la infraestructura de transporte, la inversión en educación, salud y vivienda y la ampliación del acceso a estos servicios- que, no siendo de raíz netamente regional, sí han repercutido de distintas formas en las regiones del país.

A modo de síntesis, diremos que la Región de Antofagasta, definida como ganadora, además de crecer 
por sobre el promedio nacional, mejora sus indicadores de pobreza y escolaridad por sobre los promedios nacionales (cuadro 10). Algo similar ocurre con las regiones de Coquimbo y de Aysén. En cambio, las de Tarapacá y de Atacama, que también crecen dinámicamente, no disminuyen al mismo ritmo sus niveles de pobreza ni incrementan sustantivamente sus niveles de escolaridad. En el otro extremo, las regiones de Magallanes (declinante), y de Valparaíso y de O'Higgins (estancadas), que crecen con menos dinamismo, disminuyen considerablemente sus niveles de pobreza. Sin lugar a dudas, en estos casos el avance social ha sido el resultado de las políticas sociales del gobierno central, que han repercutido favorablemente en estas regiones.

De lo anterior se desprende que, siendo el crecimiento muy importante para que mejore la situación social, estos dos fenómenos y sus dinámicas no siempre van de la mano. Es la política social la que puede y debe desempeñar un papel muy significativo en la consecución de ambos resultados.

Con el ánimo de resaltar la heterogeneidad de las situaciones que se pueden dar y con miras a entender la importancia, en lo que a políticas regionales se refiere, de identificar políticas diferenciadas para enfrentar características distintas, se presenta en seguida una tipificación de las regiones que deriva del análisis realizado:
- Regiones ganadoras, con recursos naturales exportables

- Regiones mineras que tienen características de economías de enclave con dudosas capacidades de articulación local. Sin embargo, de esa capacidad dependen sus posibilidades de desarrollo. Aquí se encuentran las regiones de Tarapacá, Antofagasta, Atacama y Coquimbo.

- Regiones agroexportadoras que han modernizado fuertemente una parte de su sector agrícola. Igualmente, aunque en términos distintos que frente a las regiones mineras, se mantiene la inquietud acerca de las posibilidades de estos sectores para generar sinergias positivas (encadenamientos) con el resto del tejido económico local. En este caso se encuentra la Región del Maule.

- Regiones ganadoras que han potenciado recursos locales latentes, normalmente primarios, como el salmón en la Región de Los Lagos, cuyo desafío es articular la economía regional a partir de un sector más dinámico.

- Regiones ganadoras que albergan áreas metropolitanas, como la Región Metropolitana de Santiago, fuertemente orientada a actividades financieras y de servicios.

CUADRO 10

Chile: tasa de crecimiento del PIB per cápita en 1990-2002 y evolución de las tasas de pobreza y años de escolaridad en 1990-2003, por regiones

\begin{tabular}{|c|c|c|c|c|c|c|c|c|}
\hline \multirow{2}{*}{ Regiones } & \multirow{2}{*}{ Cuadrante $^{\mathrm{a}}$} & \multirow{2}{*}{$\begin{array}{c}\% \text { de crecimiento } \\
\text { del PIB p. cap. } \\
1990 / 2002\end{array}$} & \multicolumn{3}{|c|}{$\%$ de pobreza } & \multicolumn{3}{|c|}{ Años de escolaridad } \\
\hline & & & 1990 & 2003 & Variación & 1990 & 2003 & Variación \\
\hline De Tarapacá & G & 4,3 & 28,3 & 18,5 & $-34,8$ & 10,0 & 10,8 & 0,8 \\
\hline De Antofagasta & G & 5,5 & 34,1 & 11,2 & $-67,1$ & 9,8 & 10,9 & 1,2 \\
\hline De Atacama & G & 5,0 & 34,2 & 24,9 & $-27,3$ & 8,9 & 9,6 & 0,7 \\
\hline De Coquimbo & $\mathrm{C}$ & 4,2 & 45,3 & 21,5 & $-52,4$ & 8,5 & 9,7 & 1,2 \\
\hline De Valparaíso & $\mathrm{E}$ & 2,8 & 43,2 & 19,4 & $-55,1$ & 9,3 & 10,3 & 1,0 \\
\hline De O’Higgins & $\mathrm{E}$ & 3,4 & 41,1 & 19,2 & $-53,3$ & 8,0 & 9,1 & 1,0 \\
\hline Del Maule & $\mathrm{C}$ & 4,0 & 42,8 & 23,1 & $-46,0$ & 7,5 & 8,7 & 1,2 \\
\hline De Bío Bío & $\mathrm{E}$ & 2,3 & 47,5 & 28,0 & $-41,0$ & 8,3 & 9,5 & 1,3 \\
\hline De La Araucanía & $\mathrm{E}$ & 3,4 & 46,4 & 29,7 & $-35,9$ & 7,8 & 9,1 & 1,2 \\
\hline De Los Lagos & $\mathrm{C}$ & 4,4 & 39,8 & 21,8 & $-45,2$ & 7,8 & 9,0 & 1,2 \\
\hline De Aysén & G & 4,4 & 32,8 & 14,2 & $-56,7$ & 7,8 & 9,0 & 1,2 \\
\hline De Magallanes & $\mathrm{D}$ & 1,2 & 30,0 & 12,3 & $-59,0$ & 8,8 & 10,2 & 1,3 \\
\hline R. Metropolitana & $\mathrm{D}$ & 3,3 & 33,0 & 13,1 & $-60,4$ & 9,9 & 11,0 & 1,1 \\
\hline Chile & & 3,5 & 38,6 & 18,7 & $-51,6$ & 9,0 & 10,2 & 1,1 \\
\hline
\end{tabular}

Fuente: MIDEPLAN, Encuesta de Caracterización Socioeconómica Nacional (CASEN), y elaboración propia.

a $\mathrm{G}=$ regiones ganadoras. $\mathrm{C}=$ regiones convergentes. $\mathrm{E}=$ regiones estancadas. $\mathrm{D}=$ regiones declinantes. 
- Regiones perdedoras con economías rurales de baja productividad. Son regiones tradicionalmente pobres que siguen siendo pobres, como la Región de La Araucanía. La cuestión esencial en ellas es identificar políticas, normalmente de carácter compensatorio, para generar algún efecto, ojalá multiplicador, sobre estas alicaídas economías. Estas medidas probablemente comenzarían por fortalecer el capital humano y la infraestructura.

- Regiones perdedoras que se han desindustrializado fuertemente, como la del Bío Bío y la de Valparaíso. En ellas hubo en el pasado importantes procesos de industrialización y, producto de la apertura, no han logrado reconvertir sus economías.

\section{Bibliografía}

CEPAL (Comisión Económica para América Latina y el Caribe) (2001): La inversión extranjera en América Latina y el Caribe. Informe 2000, LC/G. 2125-P, Santiago de Chile. Publicación de las Naciones Unidas, $\mathrm{N}^{\circ}$ de venta: S.01.II.G.12.

Moguillansky, G. (1999): La inversión en Chile: ¿el fin de un ciclo en expansión? Santiago de Chile, Fondo de Cultura Económica/ CEPAL.
Montero, C. (2004): Formación y desarrollo de un cluster globalizado: el caso de la industria del salmón en Chile, serie Desarrollo productivo, No 145 , LC/L.2061-P, Santiago de Chile. Publicación de las Naciones Unidas, $\mathrm{N}^{\circ}$ de venta: S.04.II.G.5.

Muñoz, O. (2008): Globalización y desarrollo exportador chileno: el rol de los clusters de recursos naturales, Santiago de Chile. 